\title{
GASTRIC SECRETION AFTER HISTAMINE: ITS EVALUATION AS A QUANTITATIVE TEST IN DIGESTIVE DISORDERS
}

\author{
By GEORGE D. GAMMON ${ }^{1}$ AND T. GRIER MILLER \\ (From the Gastro-Intestinal Section of the Medical Clinic, University Hospital, and the \\ John Herr Musser Department of Research Medicine, University of \\ Pennsylvania, Philadelphia)
}

(Received for publication June 17, 1931)

INTRODUCTION

With the development of a simple technic for fractional gastric analysis by injecting histamine subcutaneously as a stimulant for stomach secretion, we adopted this method as a routine procedure; for it seemed to offer advantages over the gruel meal because it eliminated the factors of dilution and buffering, and also because it afforded a method of determining more accurately the volume of juice secreted by the stomach. In time, however, because of the wide variations in the height of the acidity curves, obtained irrespective of the ultimate clinical diagnoses, we began to doubt its value. We have undertaken, therefore, to compare the results with histamine with those obtained after the gruel meal and after Liebig's extract.

Few studies have been reported of gastric secretion of normal persons after the injection of histamine. Schiff (1) found that "of 33 normal males 26 showed acidities of $120 \mathrm{cc} . N / 10$ per $100 \mathrm{cc}$. or less, 7 greater than 120; of 33 normal females 24 showed acidities of 120 or less, 9 over 120." These figures give little idea of the distribution of his figures for the acidity; but from the spot diagram of highest total acidity attained in a recent series of normals, reported by Polland and Bloomfield (2), it is evident that the figures are rather evenly distributed between 40 and 150.

\section{METHOD OF STUDY}

The first method of study was to compare the results obtained by submitting 130 patients to the histamine test $(a)$ with those secured by

1 Edward W. Bok Fellow in Clinical Medicine. 
TABLE 1

Diagnoses of patients submitted to histamine test

\begin{tabular}{|c|c|}
\hline Diagnosis & $\begin{array}{l}\text { Number } \\
\text { of cases }\end{array}$ \\
\hline 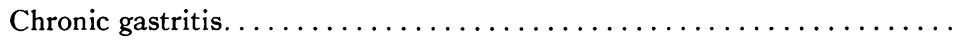 & 5 \\
\hline 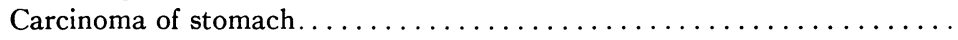 & 3 \\
\hline Gastric polyposis and hypertrophied mucous membrane $\ldots \ldots \ldots \ldots \ldots$ & 2 \\
\hline Functional gastric disturbance (secretory or motor) $\ldots \ldots \ldots \ldots \ldots$ & 6 \\
\hline 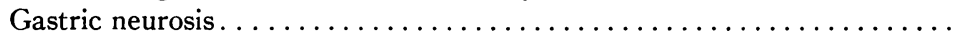 & 1 \\
\hline 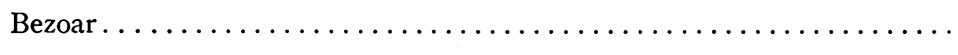 & 1 \\
\hline 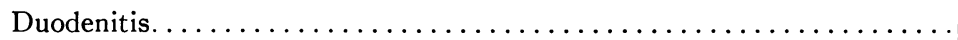 & 8 \\
\hline 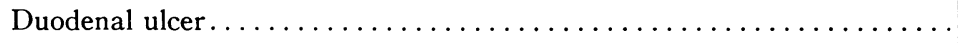 & 16 \\
\hline Duodenal ulcer with perforation (postoperative) $\ldots \ldots \ldots \ldots \ldots$ & 2 \\
\hline Duodenal ulcer, jejunal ulcer postoperatively $\ldots \ldots \ldots \ldots \ldots \ldots$ & 2 \\
\hline Duodenal ulcer, gastric ulcer (postoperative) $\ldots \ldots \ldots \ldots \ldots \ldots \ldots$ & 1 \\
\hline 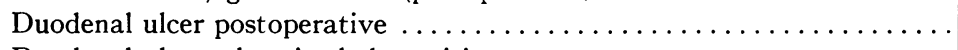 & 1 \\
\hline Duodenal ulcer, chronic cholecystitis . . . . . . . . . . . . . . . & 1 \\
\hline 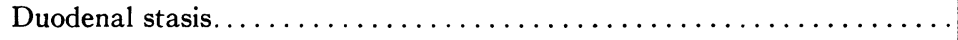 & 6 \\
\hline 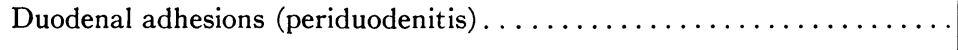 & 8 \\
\hline 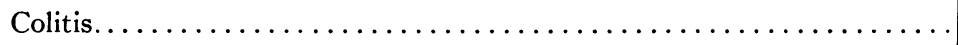 & 5 \\
\hline 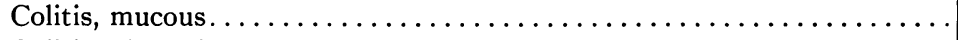 & 2 \\
\hline 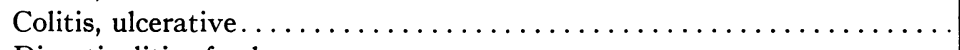 & 2 \\
\hline 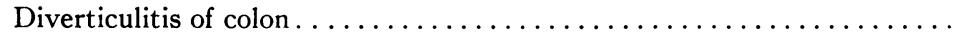 & 1 \\
\hline 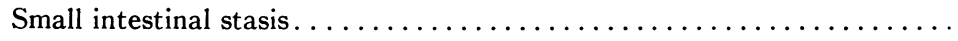 & 1 \\
\hline 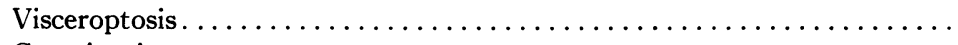 & 4 \\
\hline 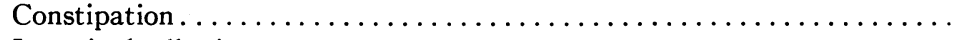 & 3 \\
\hline 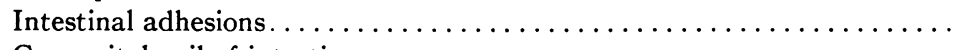 & 3 \\
\hline 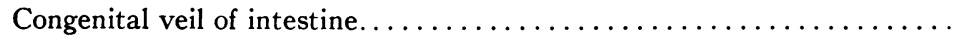 & 3 \\
\hline 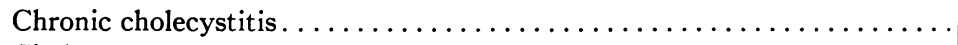 & 17 \\
\hline 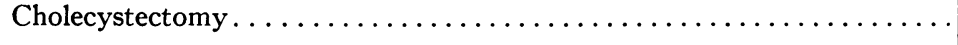 & 7 \\
\hline 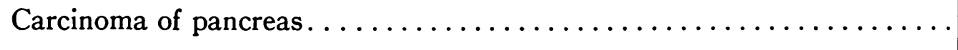 & 1 \\
\hline 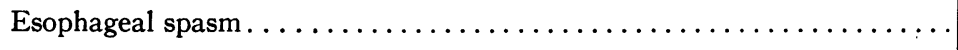 & 2 \\
\hline 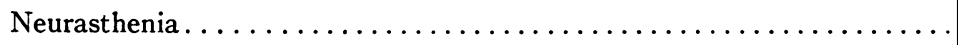 & 8 \\
\hline 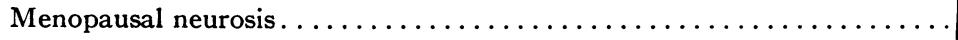 & 3 \\
\hline 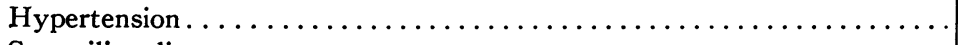 & 2 \\
\hline 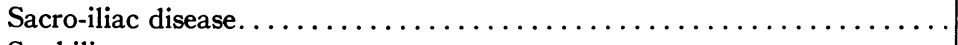 & 1 \\
\hline Syphilis. . . . . . . . . . . . . . . . . . . . . & 1 \\
\hline Hypothyroid and hypopituitary function $\ldots \ldots \ldots \ldots \ldots \ldots \ldots$ & 1 \\
\hline Total. . & 130 \\
\hline
\end{tabular}


us on a group of patients in the same age decade and with the same diagnoses tested by the gruel meal, and $(b)$ with those secured by Farr (3) on a group of patients whose secretion was stimulated by Liebig's beef extract. The diagnosis of the 130 patients undergoing the histamine test are listed in Table 1. Farr's patients had various psychoses but were in good physical condition.

The second method of study was to compare the results obtained by performing both the histamine and the oatmeal gruel tests on a group of 39 patients. Each test was made one or more times. The diagnoses of this group are listed in Table 2 .

TABLE 2

Diagnoses of patients submitted to both histamine test and fractional test meal

\begin{tabular}{|c|c|}
\hline Diagnosis & $\begin{array}{l}\text { Number } \\
\text { of cases }\end{array}$ \\
\hline 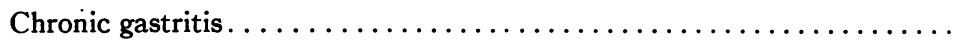 & 2 \\
\hline Polyposis of stomach and hypertrophied mucous membrane .......... & 2 \\
\hline 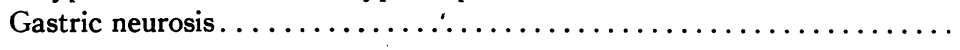 & 1 \\
\hline 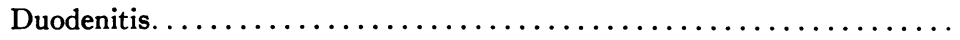 & 5 \\
\hline 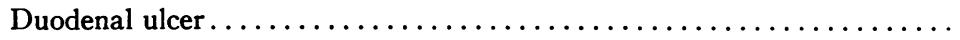 & 4 \\
\hline 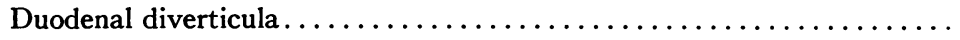 & 1 \\
\hline 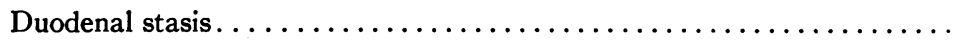 & 1 \\
\hline 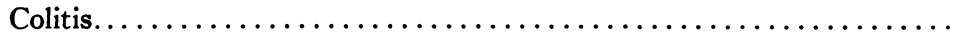 & 2 \\
\hline 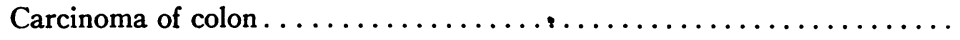 & 1 \\
\hline 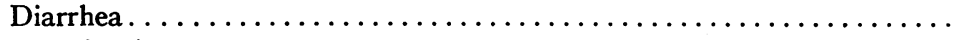 & 1 \\
\hline 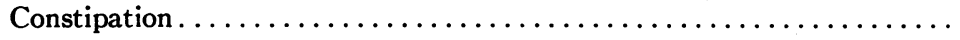 & 4 \\
\hline 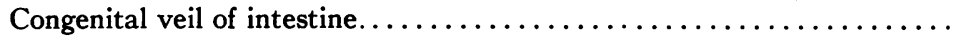 & 2 \\
\hline 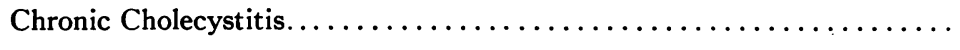 & 3 \\
\hline 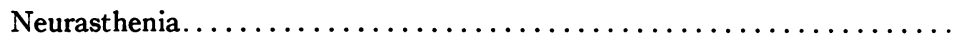 & 2 \\
\hline Addison's anemia..$\ldots \ldots \ldots \ldots \ldots \ldots$ & 1 \\
\hline 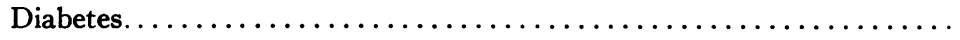 & 2 \\
\hline Arthritis, Neisserian . . . . . . . . . . . . . . . . . . . . & 3 \\
\hline 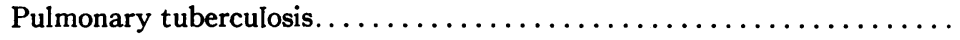 & 1 \\
\hline 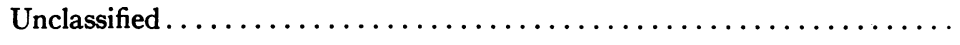 & 1 \\
\hline 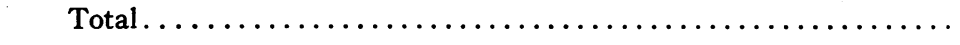 & 39 \\
\hline
\end{tabular}

All patients had been thoroughly studied by radiological investigation, and in some instances the diagnosis was established at operation. 


\section{Technic of histamine test}

After an all-night fast, the fasting gastric contents were removed, as completely as possible, through a duodenal tube passed into the stomach; this specimen was discarded. Juice secreted during the next two 15-minute periods was allowed to syphon off in order to establish the rate of secretion before stimulation: these specimens were labelled "fasting content." Histamine (ergamine acid-phosphate $1: 1000$ solution) $0.3 \mathrm{cc}$. was then administered hypodermically. The resulting juice was collected by syphonage for one hour or more; receptacles were changed at 15 minute intervals. The volume was measured, and the acidity was determined by titration with $\mathrm{N} / 50 \mathrm{NaOH}$ using Topfer's reagent and phenolphthalein as indicators. The acidity was expressed in the usual manner of cc. $N / 10$ acid per $100 \mathrm{cc}$. of gastric juice.

The juice came readily, once syphonage was started; rarely was there any difficulty from clogging of the tube. Satisfactory specimens were usually obtained, except in a few cases of achlorhydria in which secretion was sparse. Patients were instructed to expectorate all saliva during the test.

\section{Technic of Liebig's extract test}

The fasting stomach was emptied by means of a duodenal tube, and preliminary samples of contents were aspirated at 5 minute intervals for 15 minutes. One gram of Liebig's extract in $50 \mathrm{cc}$. of warm water was introduced through the tube into the stomach, and allowed to remain for 5 minutes; the stomach contents were then withdrawn as completely as possible. Subsequent samples were collected by continuous aspiration during 15 minute intervals for one hour. Practically pure stomach juice was thus obtained.

\section{Technic of gruel test meal}

The fasting gastric content was removed through a duodenal tube after the patient had fasted overnight. Three hundred cc. of oatmeal gruel, uniformly prepared and strained through gauze, was swallowed while the tube was in place. The first $10 \mathrm{cc}$. sample of gastric juice was taken at the end of 30 minutes. Following this, samples of $10 \mathrm{cc}$. were extracted at 15 minute intervals for a total of an hour and a half. The residue was then removed and its volume determined. The acidity was determined as described above. 


\section{RESULTS \\ Acidity}

The values for maximal free acid attained in each test after histamine for the whole group, excluding those cases diagnosed as duodenal ulcer or duodenitis, are presented in Fig. 1. The results in patients with ulcer and duodenitis are similarly illustrated in Fig. 2. Farr's data, obtained by the use of Liebig's extract, are given in Fig. 3. In Fig. 4 the results obtained after oatmeal gruel are given for a group of patients whose condition was similar to that of the group shown in Fig. 1.

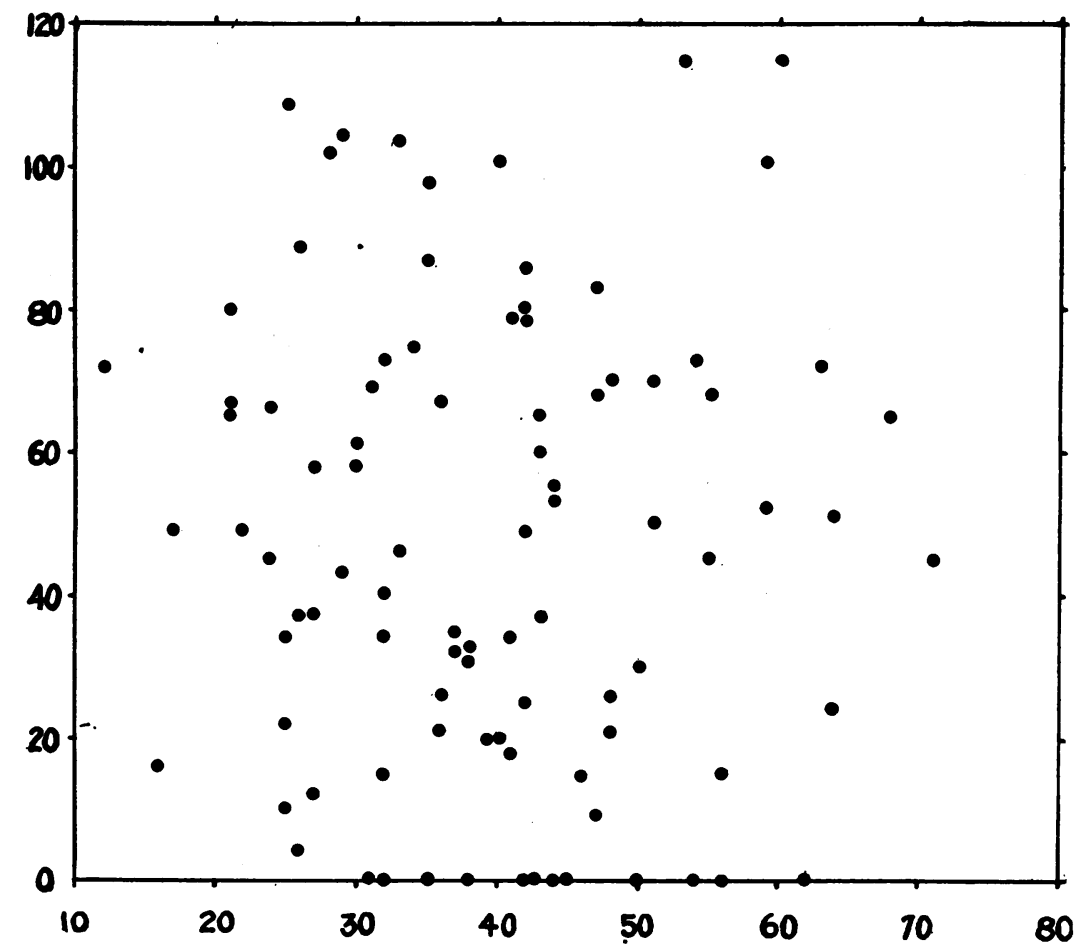

Fig. 1. Results of Histamine Test on Whole Group Exclusive of Cases with Duodenal Ulcer and Duodenitis

Age plotted as abscissae against highest free acid as ordinates.

From an examination of the results of the histamine test it is clear that the maximal acidity that was attained varied rather widely in its distribution, and did not tend to fall about the mean value. This same 
scattering of figures occurred with Liebig's extract; no correlation of these variations with the various psychoses or moods of these patients has been recognized. The observations made after oatmeal gruel on the same type of patient as that studied in the histamine test showed greater constancy in the maximal acidity.

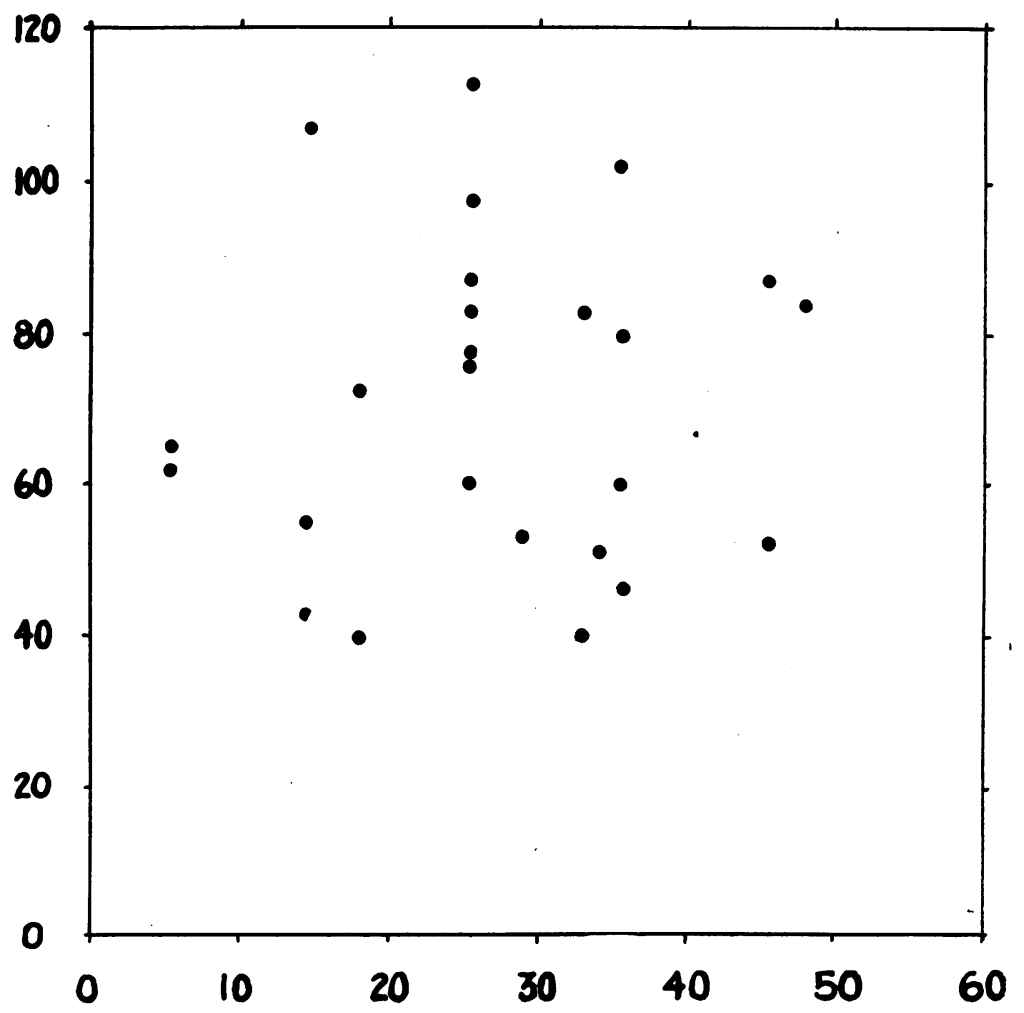

Fig. 2. Results of the Histamine Test on Cases with Duodenal UlCER AND DUODENITIS

Age plotted as abscissae against highest free acid as ordinates.

The results of studying the response to both histamine and oatmeal gruel in the same patients are illustrated in Fig. 5. There is no correlation between the acidity attained after oatmeal gruel and after histamine, nor could the variations after histamine stimulation be correlated with the diagnoses, except in the instance of the achlorhydrias. 
We thus find very variable maximal acidities following stimulation by either histamine or Liebig's extract: after both of these substances the stomach secretes into a comparatively empty lumen so that almost pure juice is obtained. The same variation in maximal acidity has been observed in normal persons after histamine (2). We know that the stomach tends to secrete a juice of high and relatively constant acid content; it is this juice, comparatively undiluted, which we recover in these tests. On the other hand, in the oatmeal gruel test the stomach

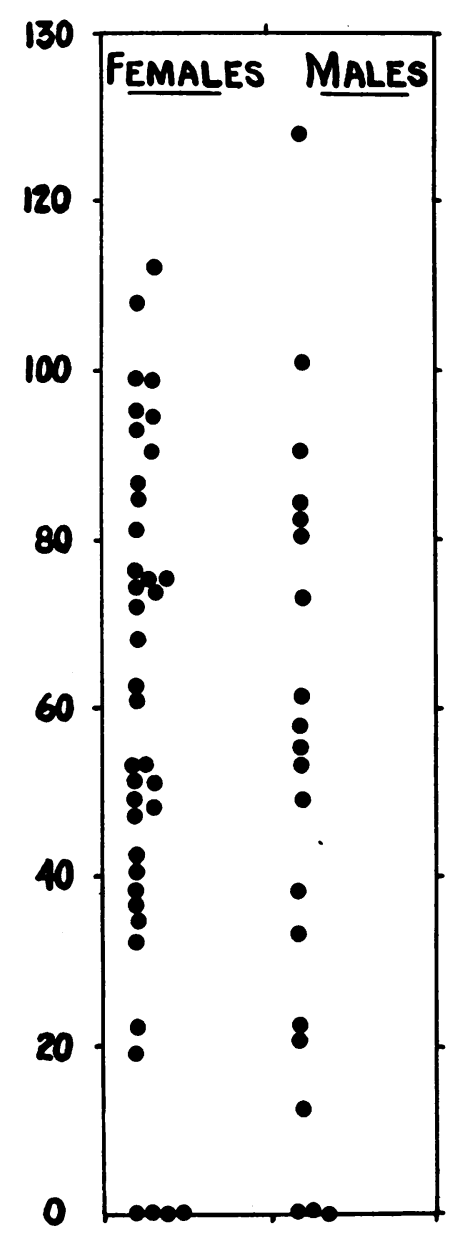

Fig. 3. Results Obtained by Farr with Ljebig's Extract Test. Highest Free Acid Attained 
secretes into a large volume of approximately neutral fluid containing buffer substances. Nevertheless the volume of oatmeal gruel and the degree of buffering do not seem to determine the maximal acidity attained after such a meal for the composition and volume of the meal

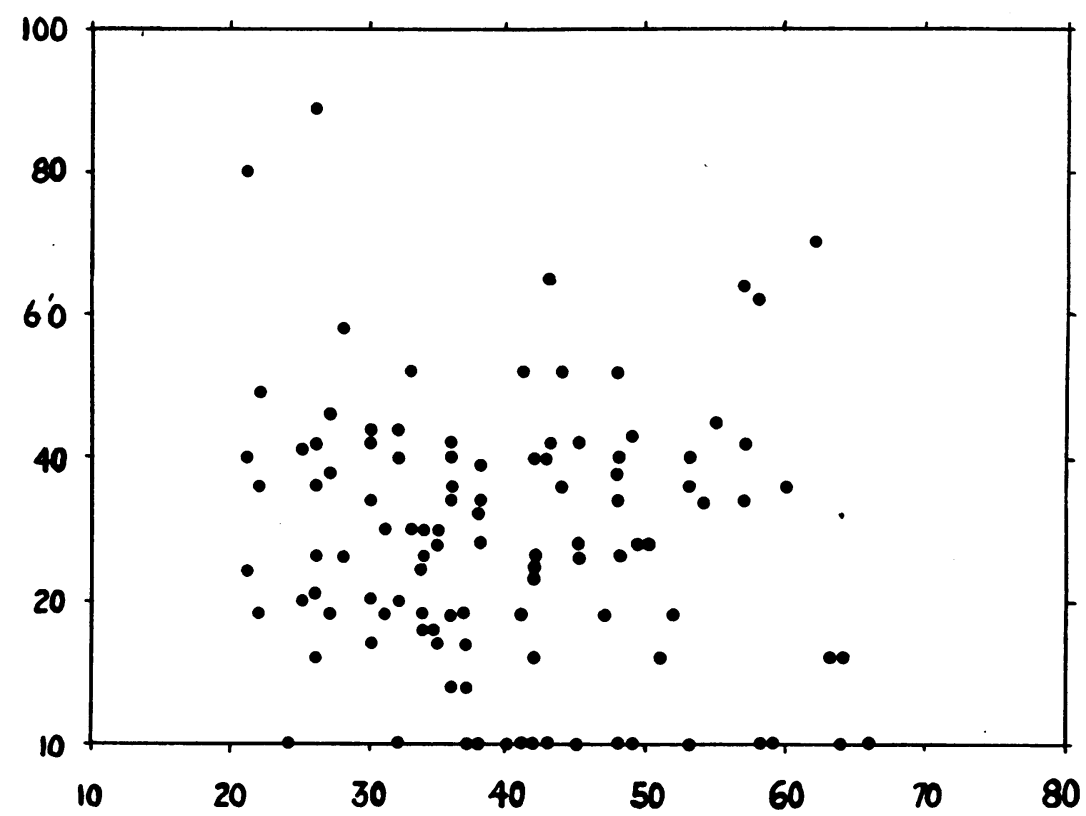

Fig. 4. Results of Gruel Meal on Whole Group Exclusive of Cases with Duodenal Ulcer and Duodenitis

Age plotted as abscissae against highest free acid as ordinates.

may be varied without materially affecting the degree of maximal acidity attained. The gastric response after oatmeal gruel gives evidence of the operation of the mechanism emphasized by Michaelis (4); "Under normal conditions the gastric secretion aims at reaching a definite $\mathrm{pH}$, and ... the amount of secreted $\mathrm{HCl}$ necessary for this purpose differs according to the acid combining capacity of the food." The effectiveness of this mechanism is limited in the test with histamine and Liebig's extract, because the stomach lacks a buffer content to permit it to operate. Since this tendency to attain a definite $\mathrm{pH}$ is masked when the histamine test is used, quantitative measurement of maximal gastric acidity, after histamine, is of little significance or diagnostic value. This conclusion has no bearing on the demonstrated value of histamine as a qualitative test of the stomach's ability to secrete acid. 


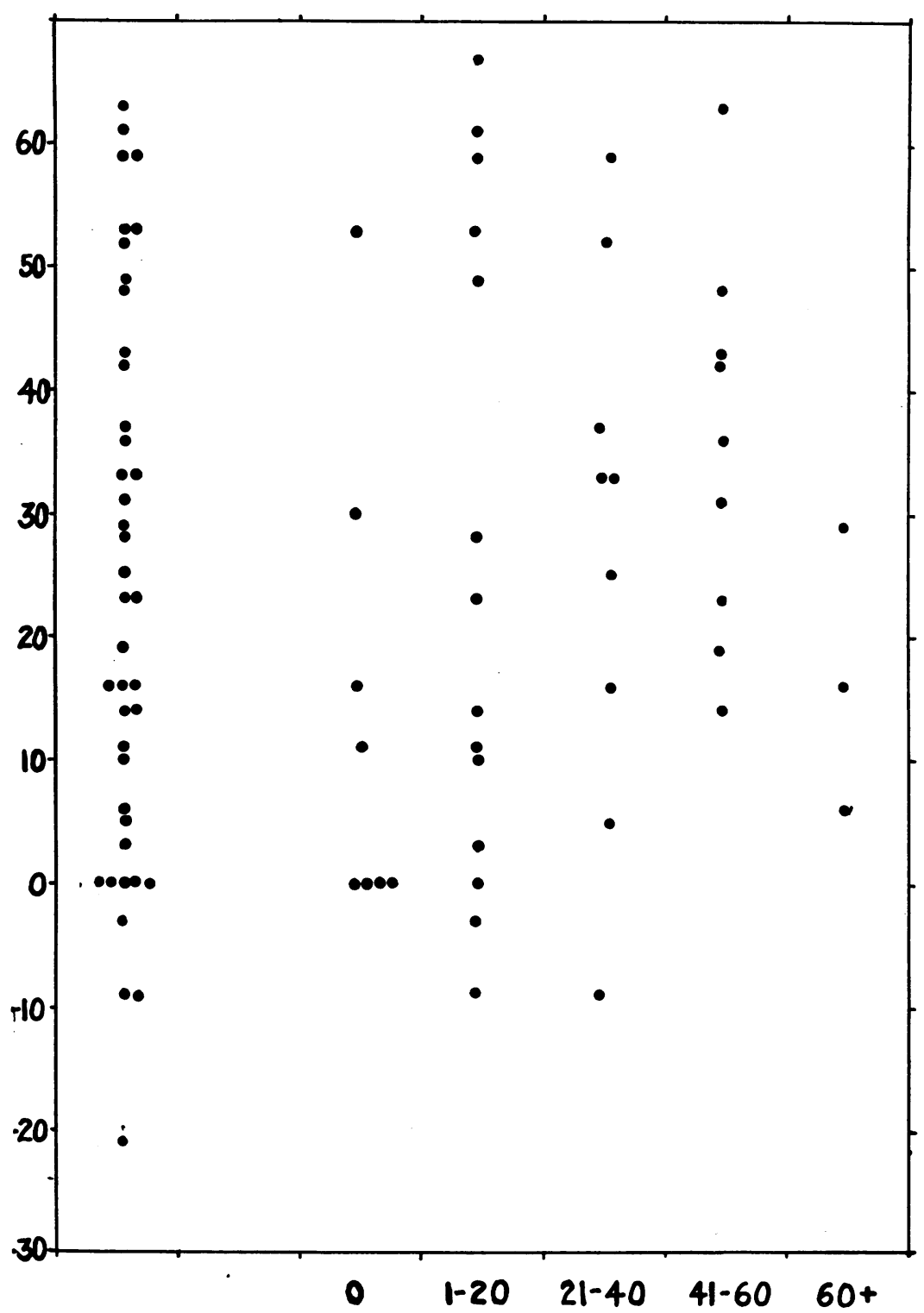

Fig. 5. Results of Histamine Test and Gruel Meal on Same Patients

The column at the left represents the difference between the highest free acid after histamine and after gruel meal. In four cases the acidity was lower after histamine. In the columns to the right the difference between the maximal acidity in the two tests is plotted as ordinates against the degree of acidity after the gruel meal as abscissae. No correlation is apparent except in half the achylias. 
Sex and acidity

In the histamine group, excluding the cases of duodenitis and ulcer, the males had an average maximal acidity of 45 , the females, 42 (Figs. 6 and 7). Bile stained samples were not used in the computations. This difference of the means of the sexes is less than its standard error and is without significance. Kohiyar (6) found, in a large series of various gastro-intestinal diseases, that the acidities after a test meal

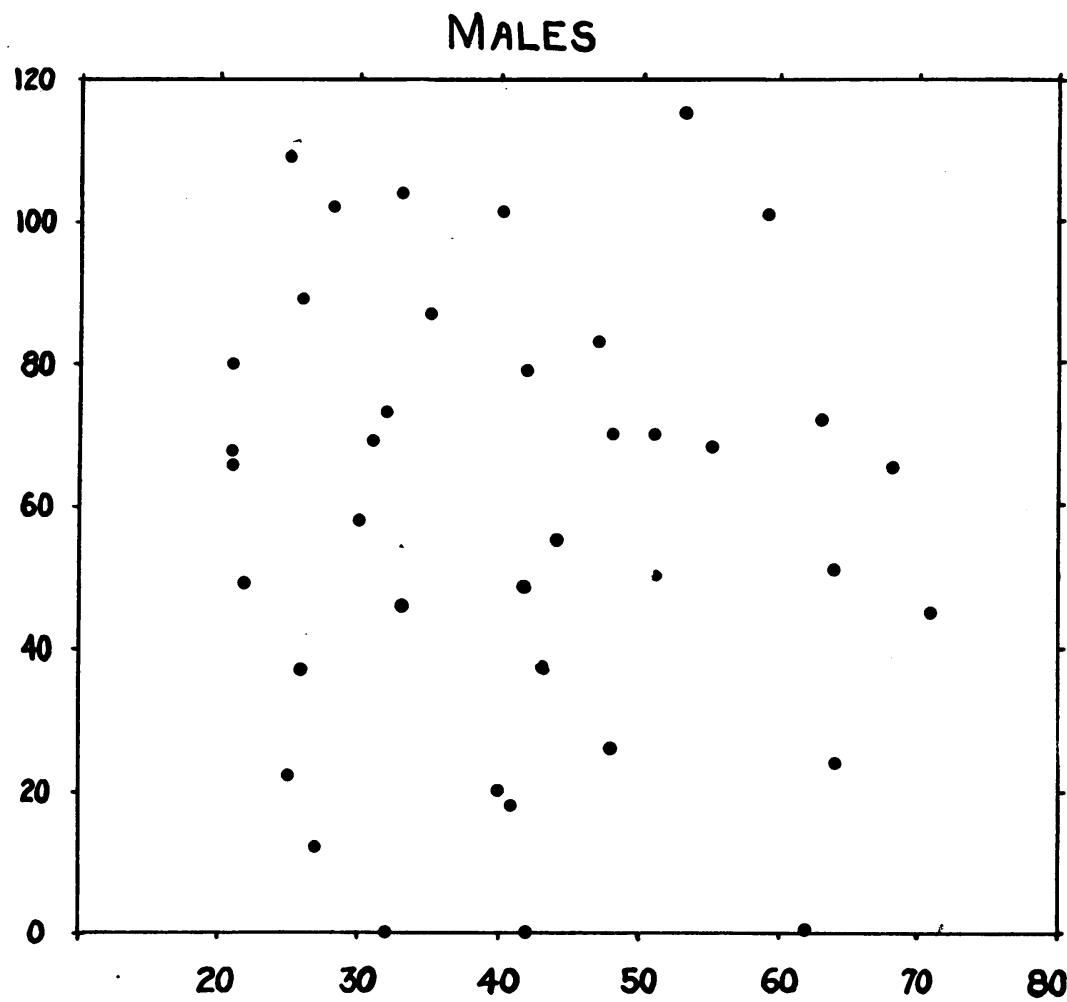

Fig. 6.

were higher in the male than in the female: the males averaged 26 , the females 20. Computation of his observations shows that the difference between his means was significantly greater than the standard error of the difference. The sex difference was not significant in our series of gruel tests. A sex difference, if it exists, may be related to the fact that males are more subject to diseases of the upper gastro-intestinal tract associated with high acidity. 


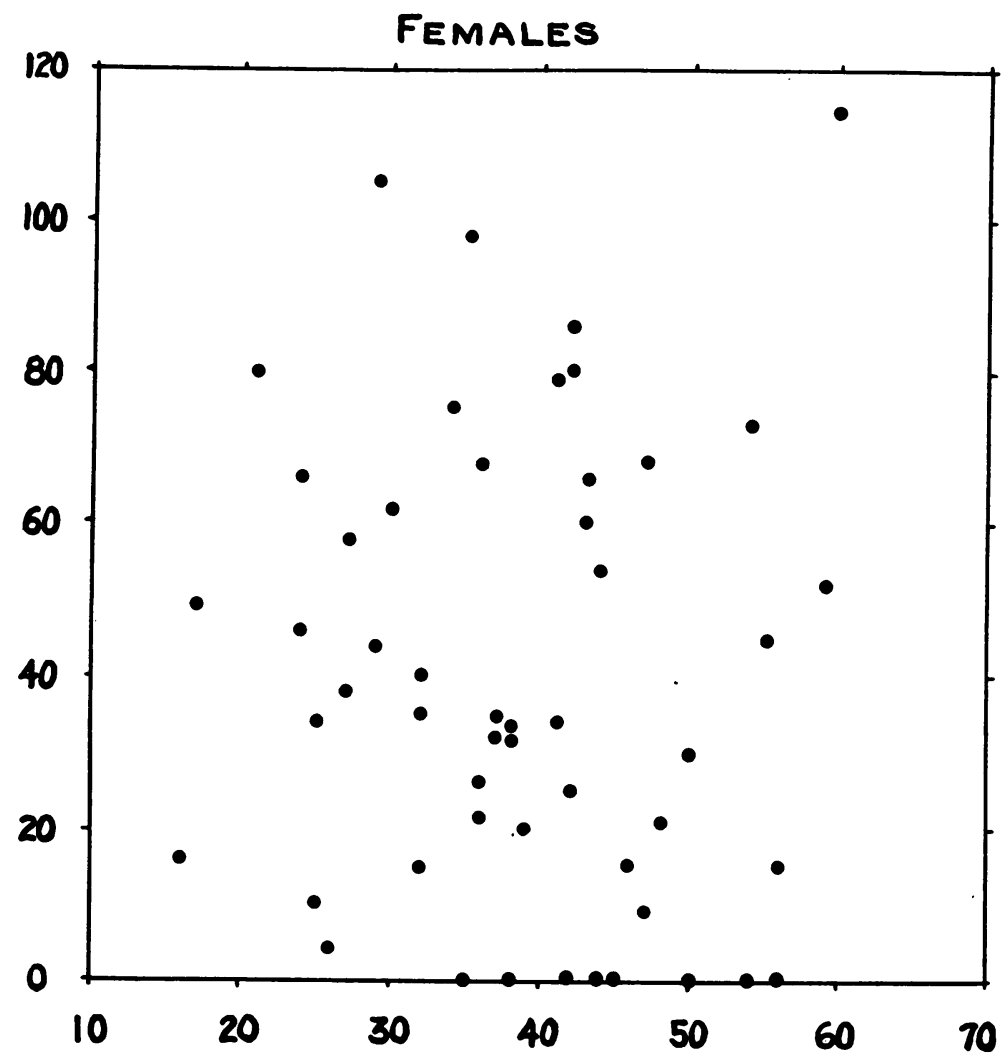

Figs. 6 and 7. Effect of Sex on the Results of Histamine Test, Excluding Cases of Duodenitis and Ulcer. Males, Fig. 6; Females, FIG. 7.

Age plotted as abscissae against highest free acid as ordinates.

\section{Age and acidity}

An increasing incidence of achlorhydria with advancing age has been noted (7), but our data when analyzed statistically show no significant decline in acidity with increasing age either with the histamine or gruel tests.

\section{Volume of secretion}

Numerous writers $(8,9$ and 10$)$ have called attention to variation in volume of secretion after histamine. For our whole group of cases, exclusive of those with duodenal ulcer and duodenitis, the highest 15 minute volume for each test is recorded in Table 3 . The averages for 
the various age decades fell between 30 and $40 \mathrm{cc}$. per 15 minutes. This agrees well with the results obtained by continuous aspiration (11) (2). The duodenal ulcer and duodenitis group averaged about $54 \mathrm{cc}$. per 15 minutes for each of the age decades from 20 to 50 . There were so few cases of cancer in our group that no conclusions can be drawn from

TABLE 3

Results of histamine test. Highest 15 minute volume of secretion and age of subject

\begin{tabular}{|c|c|c|c|c|c|c|}
\hline \multirow{2}{*}{$\begin{array}{l}\text { Highest } \\
\text { volume } \\
\text { per } 1.5 \\
\text { minutes }\end{array}$} & \multicolumn{6}{|c|}{ Age } \\
\hline & $10-20$ & $21-30$ & $31-40$ & $41-50$ & $51-60$ & $61-$ \\
\hline $\begin{array}{c}c c . \\
91-100\end{array}$ & cases & cases & cases & $\begin{array}{c}\text { cases } \\
1\end{array}$ & cases & cases \\
\hline $81-90$ & & & & & & \\
\hline $71-80$ & & & & & & \\
\hline $61-70$ & & 2 & 2 & & & \\
\hline $51-60$ & 1 & 2 & 2 & 2 & 1 & \\
\hline $41-50$ & 1 & 5 & 5 & 5 & 1 & \\
\hline $31-40$ & & 10 & 5 & 4 & 2 & 3 \\
\hline $21-30$ & & 3 & 5 & 4 & 4 & 2 \\
\hline $11-20$ & & 5 & 2 & 4 & 3 & \\
\hline $5-10$ & & 1 & 1 & 3 & & \\
\hline $\begin{array}{l}\text { Average } \\
\text { highest test }\end{array}$ & 49 & 35 & 27 & 33 & 29 & 31 \\
\hline
\end{tabular}

the tests that were made, although no striking differences were observed from the results of the whole group. The volumes ranged between 30 and $50 \mathrm{cc}$. per 15 minutes.

No striking difference, which could be attributed to age or sex, was noted in the volume secretion for the whole group.

The relation between volume and acidity after histamine is recorded 
in Table 4. There is no significant correlation. It may be noted, however, that the 10 cases with zero acidity had maximal secretion rates below $30 \mathrm{cc}$. per 15 minutes, whereas 36 of the 107 cases with measurable acidity had maximal secretion rates above $30 \mathrm{cc}$. per 15 minutes. Achlorhydrias, therefore, usually have. a low volume of secretion.

TABLE 4

Results of histamine test. Volume-acidity relation

\begin{tabular}{|c|c|c|c|c|c|c|c|c|c|c|c|}
\hline \multirow{2}{*}{ Acidity } & \multicolumn{11}{|c|}{ Volume cc. per 15 minutes } \\
\hline & $1-5$ & $|6-10|$ & $11-20$ & $21-30$ & $31-40$ & $41-50$ & $51-60$ & $61-70$ & $71-80$ & $81-90$ & 91-100 \\
\hline $\begin{array}{c}c c . N / 10 \\
131-140\end{array}$ & cases & cases & $\begin{array}{c}\text { cases } \\
1\end{array}$ & cases & cases & cases & cases & cases & cases & cases & cases \\
\hline \multicolumn{12}{|l|}{$121-130$} \\
\hline $111-120$ & & & 1 & 3 & & 1 & & & & & \\
\hline $101-110$ & & 3 & 3 & 3 & 1 & 2 & & & & & \\
\hline $91-100$ & & & 1 & & 1 & 1 & 1 & & & & \\
\hline $81-90$ & & & 4 & 2 & & 3 & 2 & & & & \\
\hline $71-80$ & & 1 & 1 & 6 & 1 & 1 & & & & & \\
\hline $61-70$ & & & 5 & 4 & 3 & 1 & & 1 & & & \\
\hline $51-60$ & & & 2 & 3 & 1 & 1 & 1 & & & & \\
\hline $41-50$ & & 2 & 1 & 3 & 3 & 3 & 1 & 1 & & 1 & \\
\hline $31-40$ & & 2 & 4 & 2 & & & & & & & \\
\hline $21-30$ & 1 & 1 & 3 & 2 & 1 & 1 & & & & & - \\
\hline $11-20$ & & 1 & 2 & 4 & & & & & & & 1 \\
\hline $1-10$ & & & & & 2 & & & & & & \\
\hline 0 & 2 & 2 & 5 & 1 & & & & & & & \\
\hline
\end{tabular}




\section{SUMMARY}

1. The maximal free gastric acidity after histamine and after Liebig's extract in a miscellaneous group of patients varied, to a far greater extent, from the mean value than it did after the gruel meal in a similar group.

2. No correlation could be recognized between the maximal free acidity after histamine and after a gruel meal when the two tests were done on the same group of patients.

3. The variations in the acidity after histamine could not be correlated, except in the achlorhydrias, with the diagnoses of the cases.

4. No significant variations in acidity or volume secretion after histamine were noted in correspondence with the age or the sex of the patients.

5. The volume of secretion after histamine was greatest on the average in the group of duodenal ulcer and duodenitis cases, but it bore no direct relationship to the degree of acidity, except that it was lower in those cases with zero acidity.

\section{CONCLUSIONS}

1. The histamine test, though valuable to determine the ability of the stomach to secrete acid, is not serviceable as a routine method of gastric analysis, because the variations in its results are great without obvious cause.

2. The gruel meal has an advantage as a routine test of gastric acidity in that its results may be more nearly correlated with the clinical diagnoses.

3. The explanation for the superiority of the gruel meal probably lies in the fact that it contains buffer substances which permit the stomach to adjust the acidity of its total contents to a more definite level, a level which is correlated with existing conditions.

We wish to express our appreciation to Dr. J. Harold Austin for advice and criticism in this work.

\section{BIBLIOGRAPHY}

1. Schiff, L., Personal communication.

2. Polland, W. S., and Bloomfield, A. L., J. Clin. Invest., 1931, ix, 651. Normal Standards of Gastric Function. 
3. Farr, C. B., Personal communication.

4. Michaelis, L., Harvey Lectures, 1926-27, Series 22, 59. Some Problems Concerning the Gastric Juice.

5. Fisher, R. A., Statistical Methods for Research Workers. Edinburgh, 1930, 3rd ed.

6. Kohiyar, A. J., Guy's Hosp. Rep., 1926, lxxvi, 65. Notes on a Consecutive Series of 1,080 Gastric Analyses by the Fractional Method.

7. Conner, H. M., J. Am. Med. Assoc., 1930, xciv, 606. Hereditary Aspect of Achlorhydria in Pernicious Anemia. A Study of Gastric Acidity in 154 Relatives of 109 Patients Having Pernicious Anemia.

8. Carnot, P., Koskowski, W., and Libert, E., Compt. rend. Soc. de biol., 1922, lxxxvi, 575. L'influence de l'histamine sur la sécrétion des sucs digestifs chez l'homme.

9. Matheson, A. R., and Ammon, S. E., Lancet, 1923, i, 482. Observations on the Effect of Histamine on the Human Gastric Secretion.

10. Bloomfield, A. L., and Polland, W. S., J. Am. Med. Assoc., 1929, xcii, 1508. The Diagnostic Value of Studies of Gastric Secretion.

11. Austin, J. H., and Gammon, G. D., J. Clin. Invest., 1931, x, 287. Gastric Secretion after Histamine: Sodium and Potassium Content and Pepsin Estimation. 